\title{
Immediate rehabilitation of the aesthetic area in infected alveolar with rpf. 24-month follow-up.
}

\author{
Thiago Borges Mattos ${ }^{1}$, Jéssica Lemos Gulinelli², João Marcos Borges Mattos ${ }^{1}$, Walmir de Jesus Andrade ${ }^{3}$, \\ Juliana Lujan Brunetto ${ }^{4}$, Rogério Bragança de Toledo ${ }^{5}$, Pâmela Letícia Santos ${ }^{6^{*}}$
}

1. Ph.D. in Oral Biology. Coordinator of the Dental Implant Graduate Course. FUNORTE, Juiz de Fora, MG, Brazil. Professeur Fundador Le Cercle Group. 2. Professor in Undergraduate and Graduate Courses at the Universidade do Sagrado Coração (USC), Bauru, SP, Brazil.

3. Student in the Dental Implant Graduate Course. FUNORTE, Juiz de Fora, MG, Brazil.

4. Student in the Dental Prosthetics Graduate Course, Hospital for Rehabilitation of Craniofacial Anomalies (HRAC/USP), Bauru, SP, Brazil. 5. MSc student in Dental Implant, São Leopoldo Mandic, Campinas, SP, Brazil.

6. PhD in Oral and Maxillofacial Surgery and Traumatology. Professor, Department of Health Sciences, Implantology Post Graduation Course, Dental School, University Center of Araraquara, UNIARA, Araraquara, SP, Brazil.

* Corresponding Author: Pâmela Leticia dos Santos | Department of Health Sciences, University of Araraquara (UNIARA) | Rua Carlos Gomes, 1338, Centro, Araraquara-SP / Brasil - CEP 14801-340 | Phone and Fax number: +55 16 3301-7408 | e-mail: pamelalsantos@hotmail.com

Work received on 05/06/2017.

Approved for publication on 05/02/2018

\section{ABSTRACT}

Aim: This study aimed to report the clinical case of an immediate implant-supported rehabilitation in infected alveolar socket with buccal bone resorption and apical periodontitis in the teeth 42 and 43. Case Report: The patient was rehabilitated with implants associated with guided bone regeneration and immediate provisionalization. After 4 months, the custom molding was made in order to receive the metal-ceramic prosthesis. The follow-up lasted 24 months and there was no painful symptomatology, infection, implant mobility or marked peri-implant bone loss in this period. Conclusion: Therefore, the placement of immediate implants on fresh infected alveolar sockets is viable for the implant-supported rehabilitation.

\section{KEY WORDS}

Bone regeneration; Dental implants; Fibrin; Biocompatible Materials.

Rev. Clin. Periodoncia Implantol. Rehabil. Oral Vol. 11(3); 167-169, 2018.

\section{INTRODUCTION}

One of the major challenges encountered for oral rehabilitation has been the insertion of implants in the aesthetic area preserving the periimplant tissue, especially in areas with periapical lesions, making it difficult to achieve success in its finalization ${ }^{(1)}$.

The immediate rehabilitation in fresh sockets are established in the current implantology due to the preservation of adjacent structures. The minimally invasive surgical procedure is advocated for reaching the greatest success rate of immediate implant and the use of biomaterial for promoting the maintenance of the area bone volume ${ }^{(2)}$.

Among the biomaterials, the aggregated platelet and fibrin stand out, mainly due to the large number of growth factors, matrix proteins and osteoconductive and pro-angiogenic properties ${ }^{(3)}$. The association of this biomaterial with bone substitutes has achieved excellent results, as the ones described in rehabilitations with dental implants and guided bone regeneration techniques ${ }^{(4)}$.

Nevertheless, the immediate implant placement in infected tooth extraction sites is controversial due to the small samplings described in articles published worldwide ${ }^{5)}$.

Considering the challenge of rehabilitating infected areas, the case report aimed to demonstrate the implant-supported rehabilitation of the aesthetic area in infected fresh alveolar sockets, with a 24-month image and clinical follow-up.

\section{CASE REPORT}

A patient attended with a dental abscess with purulent drainage adjacent to the 42. After a thorough clinical examination and CTscan, an extensive periapical lesion associated with the \#41 and \#42 with labial bone loss, was detected (Fig. 1 and Fig. 2).

After analyzing the case, the decision was to conduct a dentoalveolar immediate-rehabilitation with dental implants of \#42 associated with apicoectomy of \#41, followed by guided bone regeneration(GBR) with hydroxyapatite collagen and autologous fibrin membranes(RPF) obtained

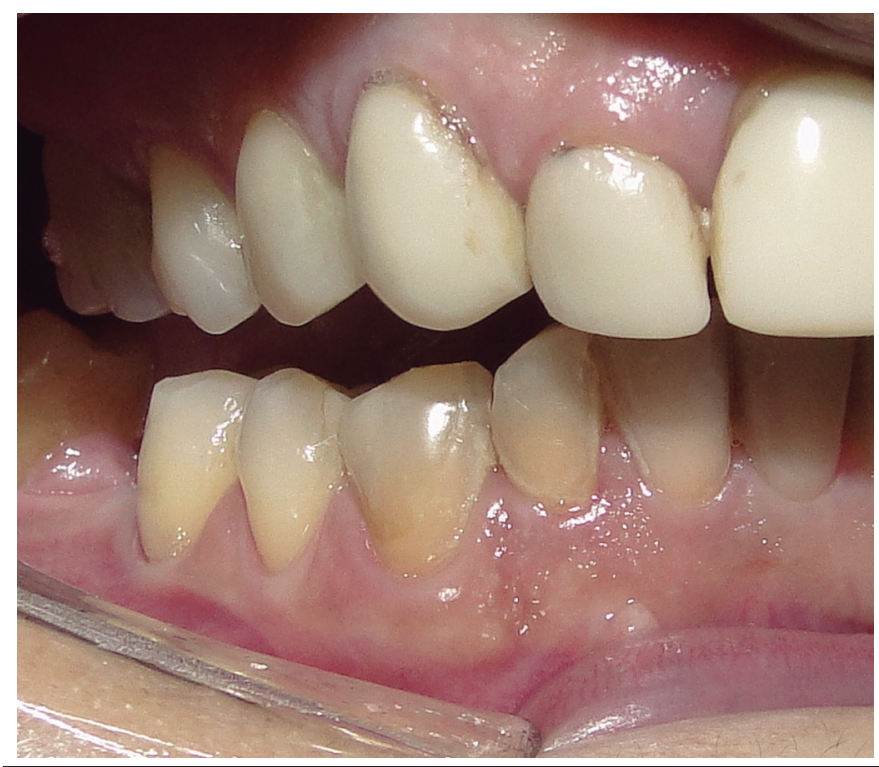

Figure 1. Clinical aspect intra oral. Note the presence of fistula in the buccal region of 42.

by the process of centrifugation and preparation. ${ }^{(4)}$

The preoperative protocol consisted of a preoperative chlorhexidine $0.12 \%$ mouth wash and the antisepsis of the face with alcohol-based chlorhexidine $0.5 \%$ and antibiotic therapy. The surgical procedure started with subperiosteal infiltration, intrasulcular incision and the mucoperiosteal detachment were conducted. The osteotomy was conducted with the piezoelectric motor for the cystic enucleation and extraction of the 

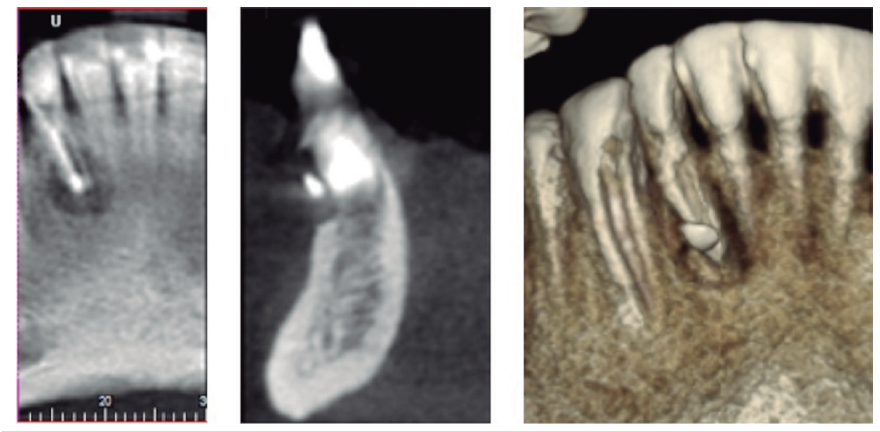

Figure 2. Tomographic evaluation and 3D reconstruction of the region 42 - Extensive cystic bone defect involving the outer cortical bone plate and endodontic therapy.

element \#42. After this stage, with a periodontal probe, the area was submitted to curettage for a complete excision of the injury, followed by the apicoectomy of the \#41(Fig. 3A).

The placement of the narrow-diameter internal hexagon implant (AXIOM 2.8-Anthogyr /France) was preceded by the achievement of a surgical alveolar socket, supporting the dental drill 2.0 on the lingual wall, with a $50 \mathrm{~N}$ torque. All acts were inspected in order to maintain the 3D position obtained through reverse planning and models of study (Fig. 3B).

Then, the adaptation of the definitive abutment was conducted, in the switching platform, through a controlled impaction system (SAFELOCKAnthogyr/France), followed by the preparation of the temporary crown in photopolymerizable composite resin Filtek ${ }^{\mathrm{TM}}$ Z350 XT(3M/ESPE-St Paul/ MN-USA), associated with the crown of the 42 that had been extracted. Such stage is crucial for obtaining and maintaining the integrity of the periodontal tissue and inserted implants, as well as its aesthetics.
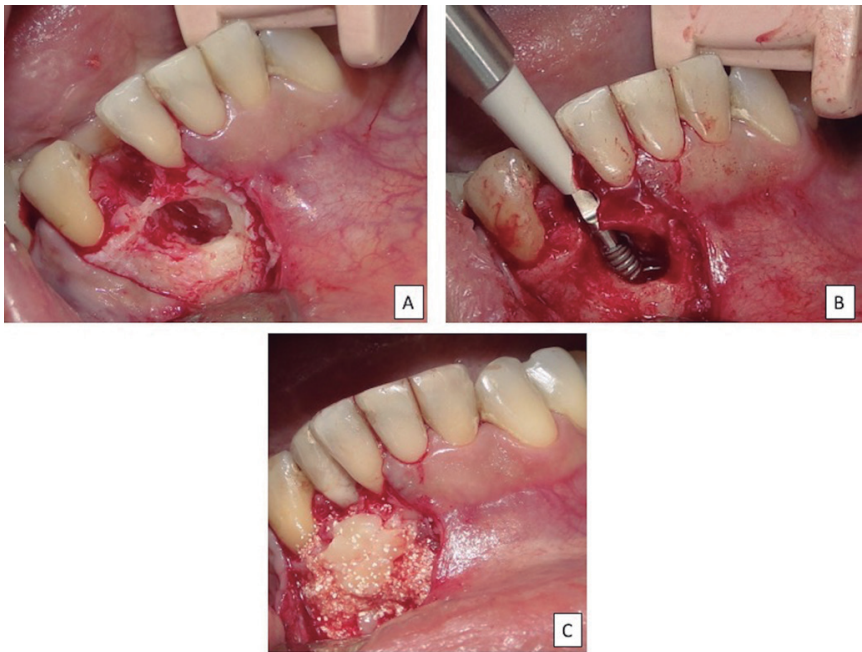

Figure 3. A-Surgical aspect after extraction of the tooth 42 and apicectomy of 41 performed with piezoelectric. Note the extent of the bone defect. B-Surgical installation of dental implant after cystic enucleation. C-Surgical aspect of guided bone regeneration for bone defect reconstruction of the buccal bone plate with bone substitute (Bonegraft), collagen membrane for rapid absorption and PRF.

After being analyzed, the temporary crown was removed so that the GBR could be conducted with the association of the EXTRAGRAPHT XG13(Sivestre lab-UNICAMP/SP-Brazil) bone substitute and the RPF. These were perforated and mixed, following the protocol already described in the literature ${ }^{(4-5)}$, with the hydroxyapatite and collagen obliterating the gap between the buccal bone defect and the wall of the inserted implant (Fig. 3C)

After the temporary crown was replaced and the occlusal adjustment was made, leaving it in infraocclusion, followed by suture which was removed after 10-post-operative days (Fig. 4). On the $180^{\text {th }}$ day of followup, the custom transfer molding was conducted in order to preserve the entire gingival framework obtained, and the subsequent production and placement of the final porcelain-fused-to-metal crown, reestablishing the function and aesthetics.

Tomographic images were captured to evaluate the neoformation and preservation of the implant and GBR obtained; there was a 24-month follow-up period. During this period, the patient reported no pain

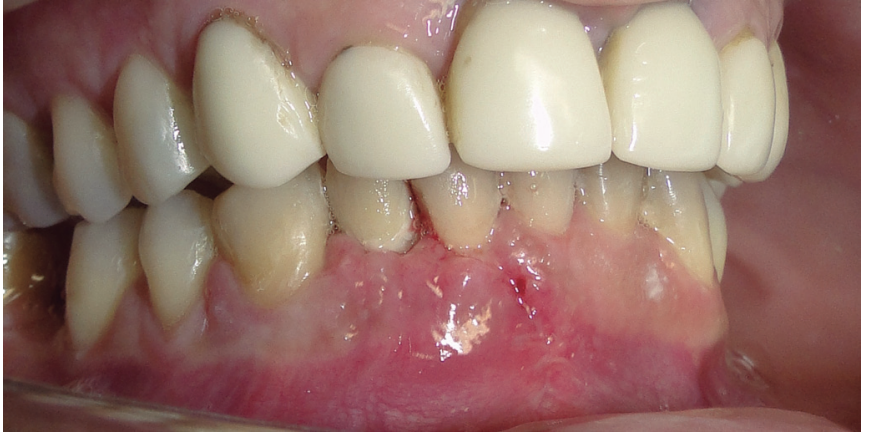

Figura 4. Clinical control 10 days after surgery showing the tissue repair process compatible with surgery, absence of inflammation, infection and wound dehiscence.

complaint. In the clinical assessment, there is no mobility of the implant or infection and the image exams show absence of radiolucency in the bone/ implant junction (Fig. 5 and 6). These factors characterize the success of the treatment.

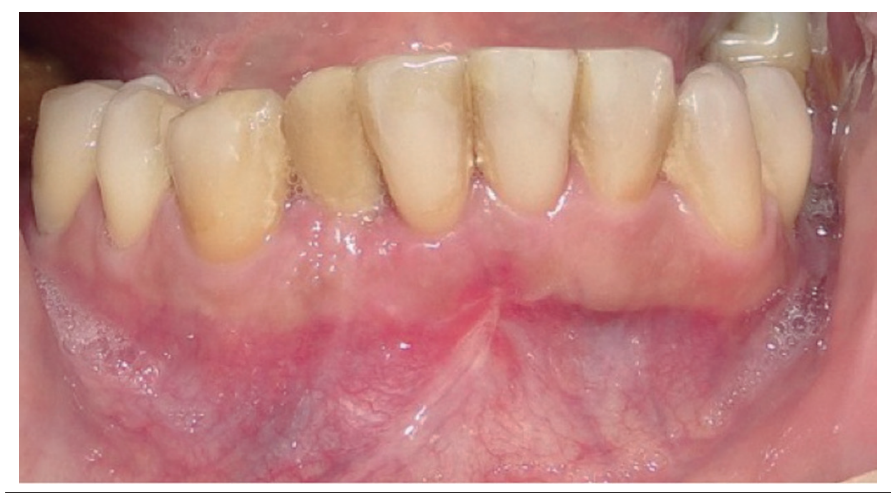

Figura 5. Clinical control 24 months after surgery: total closure of the soft tissues.

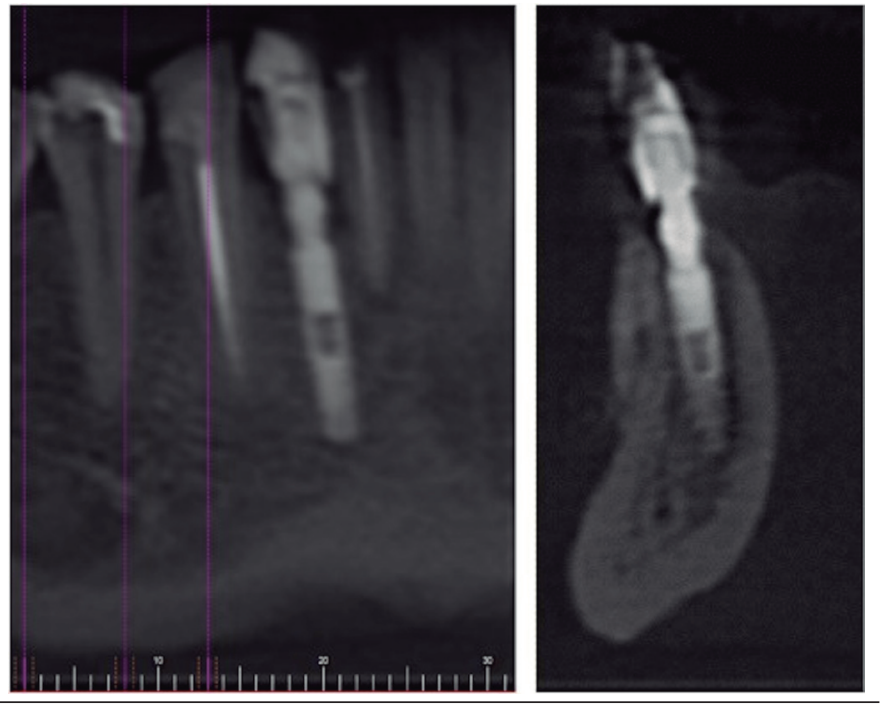

Figura 6. Tomographic control 24 months showing maintenance of the buccal bone wall and peri-implant.

\section{DISCUSSION}

The treatment for fresh alveolar sockets is satisfactorily conducted through its filling with biomaterial in order to reduce the alveolar bone reabsorption process and the treatment time. In addition, the biomaterials fixed simultaneously to the dental implant placement may benefit the functional and esthetic rehabilitation of the stomatognathic system. Therefore, exodontics followed by dental implant became one of the fastest and effective therapeutic options for tooth replacement ${ }^{(6)}$.

Nevertheless, the implant placement in infected tooth extraction sites is discussed in the scientific literature ${ }^{(7-10)}$. Marconcini et al.(2013) ${ }^{(8)}$ and 
Chrcanovic et al.(2015)(9) have reported a success rate up to $100 \%$ in the immediate implant placement in infected fresh alveolar sockets. Meltzer et al.(2012) ${ }^{(7)}$ installed 77 implants in infected alveolar sockets and, after 24 months, a rate of $98.7 \%$ were osseointegrated. Lee et al.(2015)(10) found a lower rate in areas of teeth with periapical lesions; the rate of survival of the immediate implant is $96.23 \%$ in a period of 5 years.

A significant issue for the survival of the implants placed in tooth extraction sites is the excision of the total lesion and the decontamination of the alveolar socket. If these procedures are conducted appropriately, the survival rates of implants may be statistically equal between infected and uninfected tooth extraction sites ${ }^{(8)}$.

Even with successful results regarding the placement of immediate implants in infected alveolar, the GBR procedures are commonly associated, since the combination of these therapies represents an alternative for optimizing the treatment time, the aesthetic and periodontal architecture. Therefore, this paper aimed to demonstrate the placement of immediate implant in infected fresh alveolar sockets associated with GBR through a 24-month clinical and image follow-up.

Among the materials used for the GBR, the RPF stand out. It presents a high amount of antibacterial and growth factors ${ }^{(3,10)}$ and acts in the final stage of coagulation cascade, characteristics that promote the stabilization of blood clot ${ }^{(10)}$ and bone regeneration ${ }^{(7)}$. Clinically, it has been indicated to bone defects ${ }^{(11)}$, soft tissue ${ }^{(11)}$ and maxillary sinus elevation ${ }^{(12)}$.

However, the risks of disease transmission disseminated by the halogenated transfusion need to be better evaluated, so that the autologous concentrate can be better accepted by patients. Nevertheless, there are controversies about its intervention. Pathologies, the presence of polymerized fibrin in the end of the centrifugation and no standardization of the amount of growth factors concentration, removed from platelets may interfere in the clinic results ${ }^{(13)}$.

In addition, if RPF is applied as a barrier, its mechanic resistance is of utmost importance. However, without the necessary chemistry preparation (exogenous stimulation with thrombin), it does not continue so rigid. In this reticulated consistency, RPF does not enable growth factors that are essential for certain uses ${ }^{(4)}$.

Another significant issue of this case report is the early or immediate loading. Commonly used, the implant placement in the aesthetic area helps in the maintenance of the emergency profile, in the function and conservation of alveolar socket, reducing bone resorption ${ }^{(14)}$. Therefore, in unitary implants, the dental crown of the element extracted may be used to reach a harmonic result of the smile ${ }^{(15)}$, making unnecessary the use of other means for producing the provisional prosthesis.

Based on the therapeutic protocol described above, immediate implant placement into infected alveolus was a viable option for implantsupported rehabilitation.

\section{CONFLICT OF INTEREST AND FUNDING SOURCE}

None

\section{CLINICAL RELEVANCE}

The clinical relevance is show in the challenge of rehabilitating infected areas and the emphasize the need of an appropriate treatment in the aesthetic area, including the three-dimensional planning of the implantsupported rehabilitation.

\section{References}

1. Alvarez-Camino JC, Castellón EV, Escoda CG. Immediate implants placed in fresh sockets associatedto periapical infectious processes. A systematic review. Med Oral Patol Oral Cir Bucal. 2013; 18 (5):e780-5.

2. Jang ES, Park JW, Kweon H, Lee KG, Kang SW, Baek DH, et al. Restoration of peri-implant defects in immediate implant installations by Choukroun platelet-rich fibrin and silk fibroin poder combination graft. Oral Surg Oral Med Oral Pathol Oral Radiol Endod. 2010;109:831-6.

3. Dohan DM, Choukroun J, Diss A, Dohan SL, Dohan AJ, Mouhyi J, et al. Plateletrich fibrin (PRF): a second-generation platelet concentrate. Part I: technological concepts and evolution. Oral Surg Oral Med Oral Pathol Oral Radiol Endod. 2006;101:e37-44.

4. Dohan DM, Choukroun J, Diss A, Dohan SL, Dohan AJ, Mouhyi J et al. Platelet-rich fibrin (PRF): a second-generation platelet concentrate. Part II: platelet-related biologic features. Oral Surg Oral Med Oral Pathol Oral Radiol Endod. 2006;101:e45-50. 5. Sanz M, Cecchinato D, Ferrus J, Salvi GE, Ramseier C, Lang NP, et al. Implants placed in fresh exctraction sockets in the maxila: clinical and radiographic outcomes from a 3-year follow-up examinatiom. Clin Oral Impl Res. 2014;25:321-7.

6. Dos Santos PL, de Molon RS, Queiroz TP, Okamoto R, de Souza Faloni AP, Gulinelli JL, et al. Evaluation of bone substitutes for treatment of peri-implant bone defects: biomechanical, histological, and immunohistochemical analyses in the rabbit tibia. J Periodontal Implant Sci. 2016;46(3):176-96.

7. Meltzer AM. Immediate implant placement and restoration in infected sites. Int J Periodontics Restorative Dent. 2012;32(5):169-73.
8. Marconcini S, Barone A, Gelpi F, Briguglio F, Covani U. Immediate implant placement in infected sites: a case series. J Periodontol. 2013;84(2):196-202. 9. Chrcanovic BR, Martins MD, Wennerberg A. Immediate placement of implants into infected sites: a systematic review. Clin Implant Dent Relat Res. 2015;17(Suppl 1):e1-e16.

10. Lee CT, Chuang SK, Stoupel J. Survival analysis and other clinical outcomes of immediate implant placement in sites with periapical lesions: systematic review. Int J Oral Maxillofac Implants. 2015;30(2):268-78.

11. Boora P, Rathee M, Bhoria M. Effect of platelet rich fibrin (PRF) on peri-implant soft tissue and crestal bone in one-stage implan placement: a randomized controlled trial. J Clin Diag Res. 2015;9(4):ZC18-21.

12. Li Q, Pan S, Dangaria SJ, Gopinathan G, Kolokythas A, Chu S, Geng Y, et al. Platelet-rich fibrin promotes periodontal regeneration and enhances alveolar bone augmentation. Biomed Res Int. 2013;2013:638043.

13. Lee JW, Kim SG, Kim JY, Lee JC, Choi JY, Dragos R, et al. Restoration of a periimplant defect by platelet-rich fibrina. Oral Surg Oral Med Oral Pathol Oral Radiol Endod. 2012;113(4):459-63.

14. Piccin A, Di Pierro AM, Canzian L, Primerano M, Corvetta D, Negri G, et al. Platelet gel: a new therapeutic tool with great potential. Blood Transfus. 2017;15(4):333-340. 15. Gomes FV, Volkart FB, Mayer L. Carga imediata em região anterior com utilização da coroa clínica do dente natural perdido: relato de caso. Dent. Press implantol. 2012;6(4):66-74. 